\title{
Costello syndrome model mice with a Hras G12S mutation are susceptible to develop house dust mite-induced atopic dermatitis
}

Yu Katata ${ }^{1,2}$, Shin-ichi Inoue ${ }^{1}$, Atsuko Asao ${ }^{3}$, Shuhei Kobayashi, ${ }^{3,4}$, Hitoshi Terui ${ }^{5}$, Aya Inoue-Shibui ${ }^{1}$, Taiki Abe (1), Tetsuya Niihori ${ }^{1}$, Setsuya Aiba ${ }^{5}$, Naoto Ishii ${ }^{3}$, Shigeo Kure ${ }^{2}$ and Yoko Aoki ${ }^{1}$

\begin{abstract}
Costello syndrome is an autosomal dominant disorder that is caused by germline HRAS mutations. Patients with Costello syndrome present craniofacial abnormalities, cardiac defects, and cancer predisposition, as well as skin abnormalities, including papillomas, keratosis pilaris, and eczematous dermatitis. However, the mechanisms underlying the dermatological abnormalities remain unclear. Here, we demonstrated that knock-in mice expressing an Hras G12S mutation (Hras ${ }^{G 12 S /+}$ mice) are susceptible to develop atopic dermatitis (AD)-like skin lesions, including eczema, pruritus, elevated serum IgE levels, acanthosis, and the infiltration of mast cells, basophils, and type-2 innate lymphoid cells in the dermis, after stimulation with house dust mite allergens (Dermatophagoides farinae, Dfb). Reduced skin barrier function, increased proliferation of phosphorylated ERK (p-ERK)-positive epidermal cells, and increased Th2-type cytokines as well as epithelial cell-derived cytokines, including IL-33, were observed in the skin tissue of Hras ${ }^{G / 2 S /+}$ mice compared with $\mathrm{Hras}^{+/+}$mice. Cultured $\mathrm{Hras}^{{ }^{G 125 /+}}$ keratinocytes exhibited increased IL-33 expression after Dfb stimulation. PD0325901, an MEK inhibitor, ameliorated AD-like symptoms in $\mathrm{Hras}^{\mathrm{G}}{ }^{25 /+}$ mice, showing decreased proliferation of p-ERK-positive epidermal cells and decreased expression of IL-33. Our findings indicate that the epidermis of Hras ${ }^{G 12 S /+}$ mice stimulated by Dfb strongly induced IL-33 expression and type-2 innate lymphoid cells, resulting in $\mathrm{AD}$-like skin lesions. These results suggest that the epidermis of $\mathrm{Hras}^{\mathrm{G}}{ }^{2 \mathrm{~S} /+}$ mice are prone to development of eczematous dermatitis stimulated with house dust mite allergens.
\end{abstract}

\section{Introduction}

The skin is a stratified epithelium consisting of several layers of cells in various stages of differentiation. In order to maintain normal skin homeostasis, the proliferation, differentiation, and response of epidermal cells to external stimuli must be tightly regulated ${ }^{1}$. The RAS/MAPK signaling pathway plays a crucial role in cell proliferation, differentiation, and apoptosis ${ }^{2,3}$. A strong activation of the RAS/MAPK pathway in skin is known to result in

\footnotetext{
Correspondence: Yoko Aoki (aokiy@med.tohoku.ac.jp)

'Department of Medical Genetics, Tohoku University Graduate School of Medicine, Sendai, Japan

${ }^{2}$ Department of Pediatrics, Tohoku University Graduate School of Medicine, Sendai, Japan

Full list of author information is available at the end of the article

Edited by E. Candi
}

epithelial cancers and melanoma ${ }^{4,5}$. Pigmented lesions, hyperkeratosis, pruritus, curly hair, and hyperplasia have also been observed in vemurafenib (a BRAF inhibitor)treated patients ${ }^{6}$. The balance of the RAS/MAPK signaling pathway could be particularly important for epidermal homeostasis.

Noonan syndrome, Costello syndrome, and cardiofacio-cutaneous (CFC) syndrome are phenotypically overlapping genetic disorders, characterized by craniofacial dysmorphia, congenital heart defects, and psychomotor retardation. These syndromes are commonly caused by germline mutations in components of the RAS/ MAPK pathway, termed RASopathies, which constitutively activate the RAS/MAPK pathway ${ }^{8,9}$. Of these syndromes, Costello syndrome is characterized by short

\section{(c) The Author(s) 2020}

(c) (i) Open Access This article is licensed under a Creative Commons Attribution 4.0 International License, which permits use, sharing, adaptation, distribution and reproduction c. in any medium or format, as long as you give appropriate credit to the original author(s) and the source, provide a link to the Creative Commons license, and indicate if changes were made. The images or other third party material in this article are included in the article's Creative Commons license, unless indicated otherwise in a credit line to the material. If material is not included in the article's Creative Commons license and your intended use is not permitted by statutory regulation or exceeds the permitted use, you will need to obtain permission directly from the copyright holder. To view a copy of this license, visit http://creativecommons.org/licenses/by/4.0/. 
stature, craniofacial abnormalities, congenital heart diseases, hypertrophic cardiomyopathy, and intellectual disability $^{10}$. Approximately $15 \%$ patients with Costello syndrome develop malignant tumors, including rhabdomyosarcoma and bladder carcinoma. In 2005, we identified germline HRAS mutations in patients with Costello syndrome $^{11}$. A nucleotide change that cause the substitution of glycine at codon 12 to serine (p.G12S) in one allele of HRAS has been observed in $80 \%$ of Costello syndrome patients. The G12S mutation, which has been identified in somatic cancer, is an oncogenic mutation that activates the downstream pathway. Patients with Costello syndrome develop a variety of skin abnormalities, including palmoplantar keratoderma, acanthosis nigricans, eczema, loose skin (cutis laxa), darker skin color, and papillomata around nose and anus. However, the pathogenesis of dermatological abnormalities remains unclear.

We have recently generated a strain of knock-in mice expressing an Hras G12S mutation, the most frequent mutation in Costello syndrome ${ }^{12}$, which exhibited facial dysmorphia, cardiomyocyte hypertrophy, and kidney anomalies. Impaired mitochondrial fatty acid oxidation was observed in $\mathrm{Hras}^{\mathrm{G12S} /+}$ mice fed a high-fat $\operatorname{diet}^{13}$. Skin abnormalities, including papillomas, have not been observed in young $\mathrm{Hras}^{\mathrm{G12S} /+}$ mice ( $<30$ weeks old) under specific pathogen-free conditions. In contrast, $\mathrm{Hras}^{\mathrm{G}}{ }^{\mathrm{I2S} /+}$ mice over 30 weeks of age or high-fat diet fed-Hras ${ }^{\text {G12S/+ }}$ mice had cutaneous lesions due to scratching (Supplementary Fig. 1a) under the same pathogenic-free condition. Although we have not analyzed the histology of skin of $\mathrm{Hras}^{\mathrm{G12S} /+}$ mice over 30 weeks of age, gross appearances of the skin lesions and scratching behavior suggest that they are atopic dermatitis-like. In the current study, we tested to generate experimentally induced dermatitis in $\mathrm{Hras}^{\mathrm{G12S} /+}$ mice and found that Hras ${ }^{\mathrm{G12S} /+}$ mice developed more severe atopic dermatitis (AD)-like lesions than $\mathrm{Hras}^{+/+}$mice after treatment with house dust mite allergens (Dermatophagoides farinae, Dfb). Furthermore, these $\mathrm{AD}$-like skin lesions in $\mathrm{Hras}^{\mathrm{Gl2S} /+}$ mice were reversed by treatment with an MEK inhibitor, PD0325901.

\section{Results}

\section{Dfb ointment induces AD-like skin lesions in $\mathrm{Hras}^{\mathrm{G12S} /+}$ mice}

We first tested the effect of picryl chloride, which induce contact dermatitis, and imiquimod, which induce psoriasis on the skin of $\mathrm{Hras}^{+/+}$and $\mathrm{Hras}^{\mathrm{G12S} /+}$ mice (Supplementary Fig. 1b, c), but no difference in skin lesions was observed between them (Supplementary Fig. 1d). In contrast, the treatment with Dfb ointment developed severe dermatitis, including severe erythema, hemorrhage, scarring, and eczema, in the dorsal skin of $\mathrm{Hras}^{\mathrm{G12S} /+}$ mice, but not in $\mathrm{Hras}^{+/+}$mice (Fig. 1a and Supplementary Fig. 2a). The ears of $\mathrm{Hras}^{\mathrm{GI} 2 \mathrm{~S} /+}$ mice became thick with edema, erosion, and excoriation (Fig. 1b). The dermatitis score was significantly higher in Dfb-treated Hras ${ }^{G 12 S /+}$ mice than in any other group of mice (4\% SDS-treated control $\mathrm{Hras}^{+/+}$mice, Dfb-treated $\mathrm{Hras}^{+/+}$mice, and 4\% SDS-treated control Hras ${ }^{\mathrm{GISS} /+}$ mice) on day 11 (Fig. 1c and Supplementary Table 1). Other dermatitis parameters, including the ear swelling (Fig. 1d) and the scratching behavior (Fig. 1e), increased significantly in Dfb-treated Hras ${ }^{\text {G12S/+ }}$ mice compared with Dfb-treated $\mathrm{Hras}^{+/+}$mice. Serum IgE levels were significantly higher in $\mathrm{Hras}^{\mathrm{GISS} /+}$ mice compared to Hras $^{+/+}$in nontreated baseline $(261 \pm 152.2 \mathrm{ng} / \mathrm{mL}$ vs $654 \pm 348 \mathrm{ng} / \mathrm{mL}, \quad P=0.039$, Supplementary Fig. 3). Although the difference was not statistically significant, in $4 \%$ SDS treatment groups, IgE levels were higher in Hras $^{\text {G12S/+ }}$ mice compared to Hras $^{+/+}(875 \pm 596 \mathrm{ng} / \mathrm{mL}$ vs $2500 \pm 2412 \mathrm{ng} / \mathrm{mL}, P=0.164$, Fig. 1f) as well as in the $\mathrm{Dfb}$ treatment groups $(6930 \pm 5348 \mathrm{ng} / \mathrm{mL}$ vs $14,013 \pm$ $13,951 \mathrm{ng} / \mathrm{mL}, P=0.243$, Fig. 1f). These symptoms were also seen in $\mathrm{Hras}^{+/+}$mice, but skin lesions are more severe in $\mathrm{Hras}^{\mathrm{G} 12 /+}$ mice. In both groups of mice, the IgE elevations were triggered by Dfb ointment.

We next examined if Dfb-induced dermatitis in Hras $^{\text {G12S/+ }}$ mice is caused by the same pathology as in $\mathrm{Hras}^{+/+}$mice.

Histological analysis revealed hyperkeratosis and epidermal hyperplasia in the dorsal skin of Dfb-treated $\mathrm{Hras}^{\mathrm{G12S} /+}$ mice (Fig. 2a). The epidermis of Hras ${ }^{\mathrm{G12S} /+}$ mice became thicker than that of $\mathrm{Hras}^{+/+}$mice, although Dfb treatment increased the epidermal thickness in both $\mathrm{Hras}^{+/+}$and $\mathrm{Hras}^{\mathrm{G12S} /+}$ mice (Supplementary Fig. 2b). In the AD-like skin lesions, Dfb-treated $\mathrm{Hras}^{\mathrm{G12S} /+}$ mice displayed increased number of mast cells (toluidine blue ${ }^{+}$ and tryptase $\beta 1^{+}$), a marked increase in the numbers of $\mathrm{T}$ cells $\left(\mathrm{CD} 4^{+}\right)$and dendritic cells $\left(\mathrm{MHC}\right.$ class $\left.\mathrm{II}^{+}\right)$ (Fig. 2a, b and Supplementary Fig. 2c, e). Western blotting analysis revealed that the levels of $\mathrm{CD} 4$ protein were significantly increased in Dfb-treated mice compared with control mice (Supplementary Fig. 2d). In line with the acanthosis of Dfb-treated Hras ${ }^{G 12 S /+}$ mice, an increased number of phosphohistone H3-positive cells were observed in the suprabasal epidermis layers of $\mathrm{Hras}^{\mathrm{G12S} /+}$ mice (Fig. 2b). Although phosphorylated ERK (p-ERK)positive cells were also increased in the epidermis of Dfbtreated $\mathrm{Hras}^{+/+}$and $\mathrm{Hras}^{\mathrm{Gl}}{ }^{\mathrm{SS} /+}$ mice, the immunostained area in $\mathrm{Hras}^{\mathrm{Gl}}{ }^{\mathrm{SS} /+}$ mice was significantly larger than that in $\mathrm{Hras}^{+/+}$mice. (Fig. 2b and Supplementary Fig. 2f, g). In addition, we examined the expression of filaggrin and claudin-1 as epidermal barrier markers in $\mathrm{AD}^{14-16}$. A decreased expression of claudin-1 was observed in 


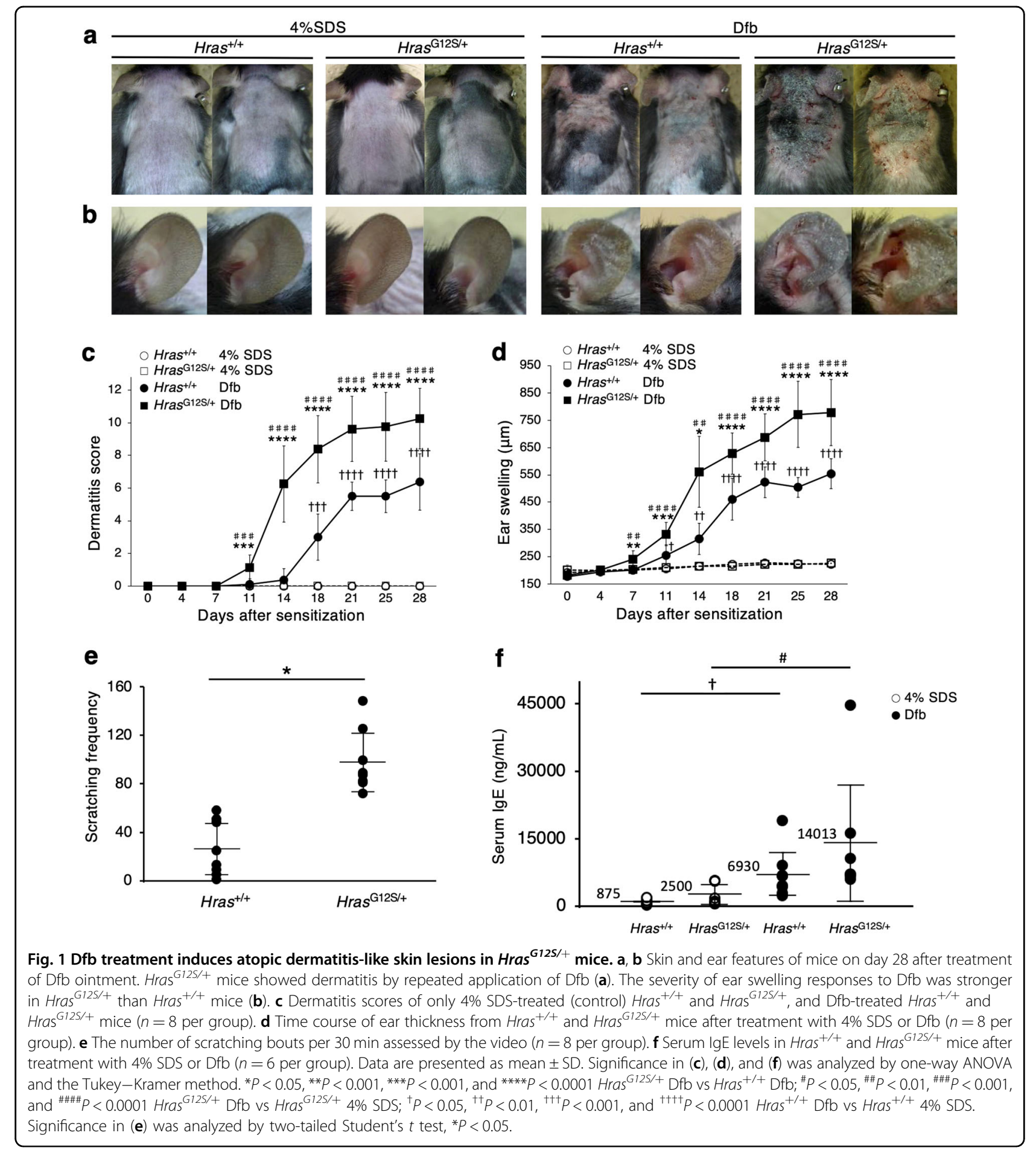

Dfb-treated Hras ${ }^{G 12 S /+}$ mice compared with control Hras $^{G 12 S /+}$ mice (Fig. 2c, d). Together, these results indicate that Dfb-applied Hras ${ }^{G 12 S /+}$ mice exhibited more severe AD-like skin lesions than $\mathrm{Hras}^{+/+}$mice, including acanthosis with hyperproliferation of p-ERK-positive cells in the epidermis, as well as increased inflammatory cells and reduced claudin-1 expression.
The skin of Dfb-applied Hras ${ }^{G 12 S /+}$ mice shows an increase of itch-associated factors and inflammatory cytokines

To further characterize the AD-like skin lesions, we evaluated the levels of the itch-associated factors and inflammatory cytokines in the skin of Dfb-treated $\mathrm{Hras}^{\mathrm{G12S} /+}$ mice. Itch-related neuronal markers, including skin Tac1, Klk7 and Klk14, mRNA levels or PAR2, and 
a

$\underset{\Upsilon}{\varpi}$
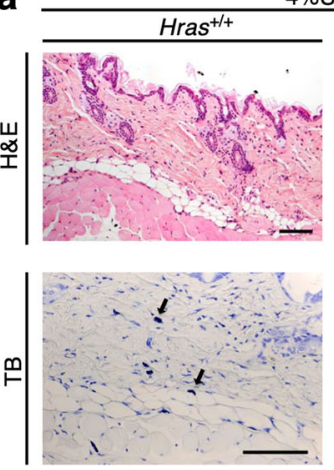

b
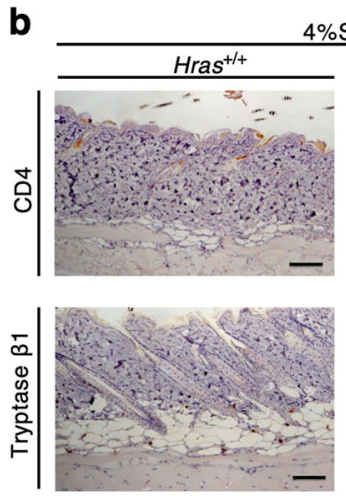

采
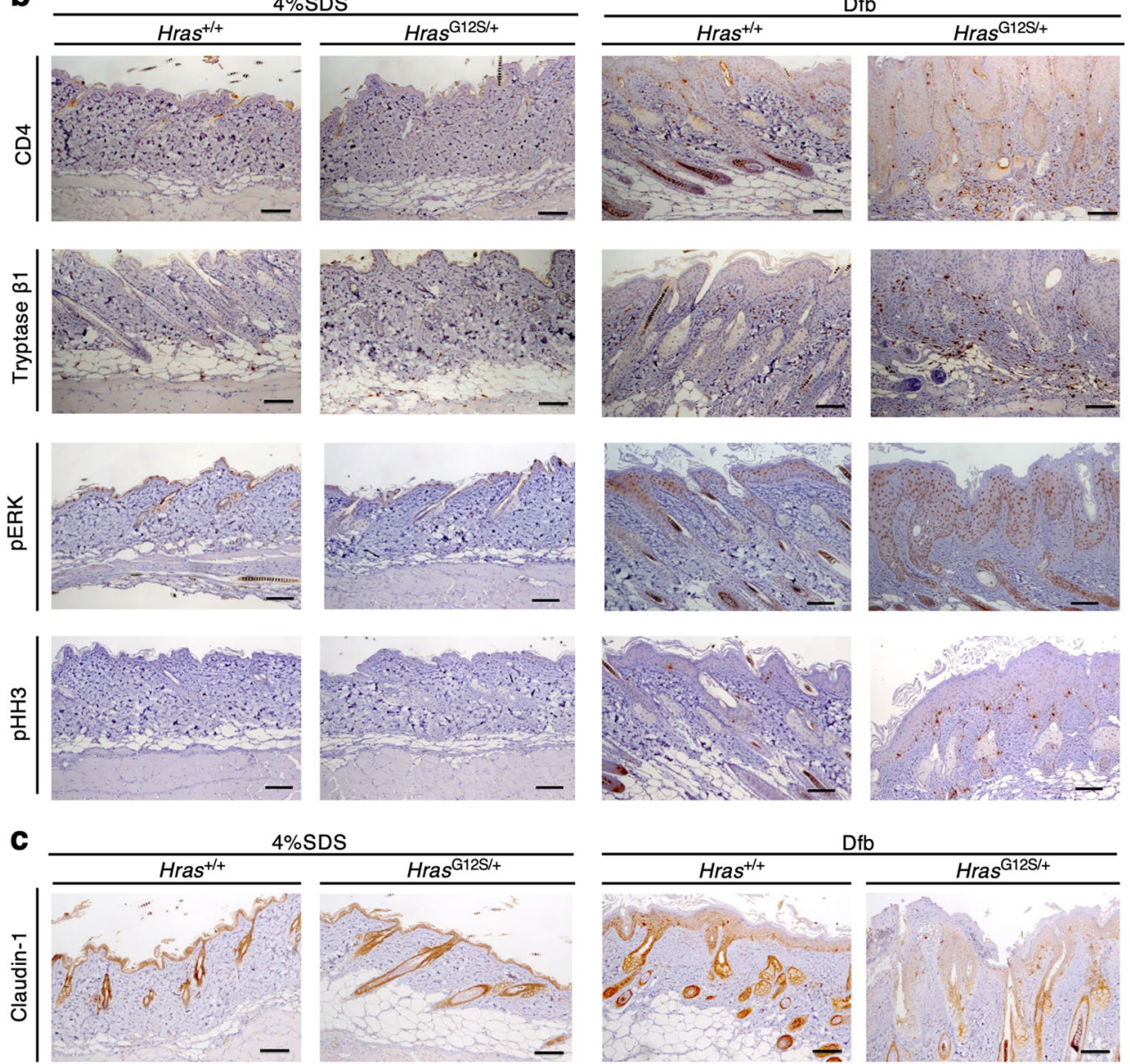

d
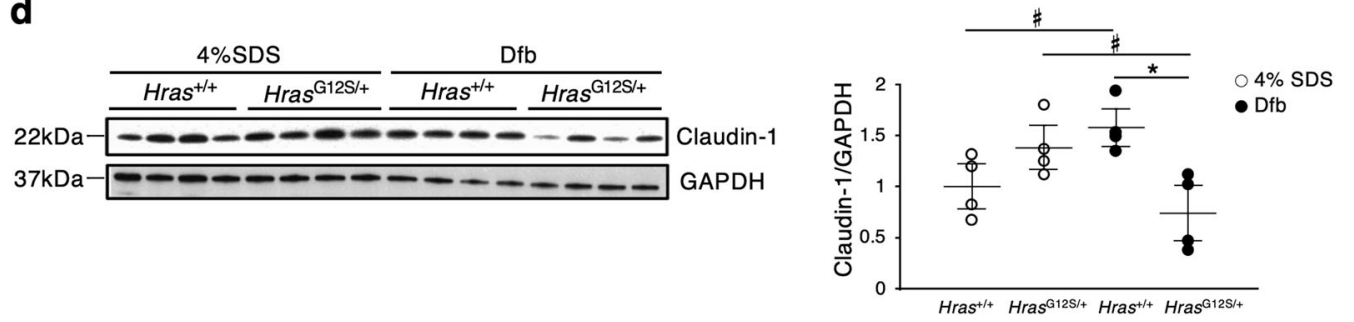

Fig. 2 (See legend on next page.) 
(see figure on previous page)

Fig. 2 Histological analysis reveals acanthosis with hyperproliferation of p-ERK-positive epidermal cells, increased inflammatory cells, and reduced claudin-1 expression in the dorsal skin of Dfb-treated $\mathrm{Hras}^{\mathrm{G}}{ }^{2 S /+}$ mice. a Skin tissue stained with H\&E and TB. b, $\mathbf{c}$ Immunohistochemistry of CD4, tryptase $\beta 1, p-E R K, p H H 3$, and claudin-1 in the skin. a-c Scale bars: $100 \mu \mathrm{m}$. $\mathbf{d}$ Lysates from the skin were immunoblotted with anti-Claudin-1 antibody. Band intensities were quantified and compared among the four groups. The expression levels were normalized to GAPDH $(n=4$ in each group). Data are presented as mean \pm SD. Significance was analyzed by one-way ANOVA and the Tukey-Kramer method. ${ }^{*} P<0.05,{ }^{\#} P<0.05$, two-tailed Student's $t$ test.

Endothelin 1 proteins ${ }^{17-20}$, were significantly higher than those in control $\mathrm{Hras}^{\mathrm{G}}{ }^{\mathrm{SS} /+}$ and Dfb-treated $\mathrm{Hras}^{+/+}$mice (Fig. 3a-c). Regarding inflammatory cytokines, the skin mRNA levels of $I l 1 \beta$ (proinflammatory cytokine), Il4 (Th2-related cytokine), and epidermal-derived cytokines, Il33 and thymic stromal lymphopoietin $(T s l p)$, were significantly elevated in Dfb-treated $\mathrm{Hras}^{\mathrm{G12S} /+}$ mice compared with control $\mathrm{Hras}^{\mathrm{GI2S} /+}$ and Dfb-treated $\mathrm{Hras}^{+/+}$ mice (Fig. 3d). IL-33 leads to the activation of type-2 innate lymphoid cells (ILC2s) through ST2, IL-33 receptor $^{21}$. In Dfb-treated Hras ${ }^{G 12 S /+}$ mice, the skin mRNA levels of St2 were also significantly increased (Fig. 3d). Immunohistochemistry analysis revealed that Dfb-treated $\mathrm{Hras}^{\mathrm{G}}{ }^{2 \mathrm{~S} /+}$ mice showed enhanced expression levels of IL-33 and TSLP in the basal epidermal layers and the surface of epidermis, respectively (Fig. 3e). Likewise, the IL-33 protein levels were significantly higher in the skin of Dfb-treated $\mathrm{Hras}^{\mathrm{G} 12 \mathrm{~S} /+}$ mice than in Dfb-treated $\mathrm{Hras}^{+/+}$ mice (Fig. 3f).

Increased numbers of ILC2 and increased IL-33 expression were observed in the epidermis of $\mathrm{Hras}^{\mathrm{G}}{ }^{25 /+}$ mice

To investigate when and how inflammatory cytokines are induced in $\mathrm{Hras}^{\mathrm{G12S} /+}$ mice, we performed flow cytometry on skin and ear samples 12 days after Dfb application, that is, once the AD-like skin lesions had begun to appear (Fig. 1c). The accumulation of basophils and ILC2s was observed on skin samples of Dfb-treated Hras $^{\text {G12S/+ }}$ mice 12 days after Dfb application (Fig. 4a). A significant increase in mast cells, eosinophils, basophils, and ILC2s was also observed in the ears of $\mathrm{Hras}^{\mathrm{G12S} /+}$ mice (Fig. 4b). On the other hand, these immune cells were hardly detected in $\mathrm{Hras}^{+/+}$and $\mathrm{Hras}^{\mathrm{G12S} /+}$ mice 12 days after 4\% SDS application (Supplementary Fig. 4). The mRNA levels of inflammatory cytokines in the skin from $\mathrm{Hras}^{\mathrm{G}}{ }^{\mathrm{SS} /+}$ mice 15 days after Dfb application showed that $I l 1 \beta$ and Il33 were significantly elevated in the skin of Dfb-treated Hras ${ }^{G 12 S /+}$ mice compared with Dfb-treated $\mathrm{Hras}^{+/+}$mice (Fig. 5a).

Atopic dermatitis is characterized by increased serum IgE, acanthosis, loss of skin barrier function, and infiltration of immune cells, including Th2 cells, dendritic cells, eosinophils, basophils, and mast cells ${ }^{22,23}$. On that account, we next examined the response of immune cells in these mice. HRAS is known to be highly expressed in the epidermal cells, but not in immune cells ${ }^{24,25}$. Indeed, no significant difference was found in the population of immune cells from the spleen and lymph node (LN). The proliferation of naive $\mathrm{CD} 4^{+} \mathrm{T}$ cells and $\mathrm{Th} 2$ immune response was comparable between $\mathrm{Hras}^{+/+}$and $\mathrm{Hras}^{\mathrm{G12S} /+}$ mice at 7 weeks of age, suggesting that AD-like dermatitis may not be caused by different response of immune cells (Fig. 6a, b). Then we examined whether an increased production of IL-33 and TSLP was observed in primary epidermal keratinocytes in response to Dfb. Six hours after Dfb stimulation, the mRNA level of $I l 1 \beta$, not $T s l p$, was significantly elevated in cultured epidermal keratinocytes of $\mathrm{Hras}^{+/+}$and $\mathrm{Hras}^{\mathrm{G12S/+}}$ mice (Fig. 5b). Notably, the mRNA levels of Il33 in the Dfb-stimulated keratinocytes of $\mathrm{Hras}^{\mathrm{G12S} /+}$ mice were significantly increased compared with those of nonstimulated Hras $^{\text {G12S/+ }}$ and Dfb-stimulated $\mathrm{Hras}^{+/+}$keratinocytes, suggesting that epidermal keratinocytes with Hras G12S mutation have increased IL-33 expression after stimulation with Dfb (Fig. 5b).

\section{PD0325901 reduces skin lesions in Dfb-stimulated Hras $^{\text {G12S/+ }}$ mice}

Treatment with MEK inhibitors ameliorates the abnormalities observed in RASopathy-related model mice $^{26-28}$. We investigated the effects of an MEK inhibitor, PD0325901, on skin lesions in Dfb-treated Hras $^{\text {G12S/+ }}$ mice (Supplementary Fig. 5a). Ten days of treatment with PD0325901 (or saline) resulted in a significant improvement of the dermatitis score and ear swelling in $\mathrm{Hras}^{\mathrm{G12S} /+}$ mice (Fig. 7a, b). PD0325901 treatment resulted in a marked reduction of epidermal thickness, mast cell numbers, and p-ERK-positive epidermal cells, as well as recovered expression levels of claudin-1 (Fig. 7c, d and Supplementary Fig. 5b, c). The mRNA levels of $I l 1 \beta, I l 4, I l 33$, St2, and Klk14 were significantly lower in the skin of PD0325901-treated $\mathrm{Hras}^{\mathrm{G12S} /+}$ mice than that of vehicle (saline)-treated Hras $^{\text {G12S/+ }}$ mice (Fig. 7e and Supplementary Fig. 5d). These results suggest that ERK inhibition partially ameliorates Dfb-induced skin lesions in $\mathrm{Hras}^{\mathrm{Gl2S} /+}$ mice.

\section{Discussion}

Here, we demonstrated that mice expressing a germline Hras G12S mutation, but not $\mathrm{Hras}^{+/+}$mice, developed 


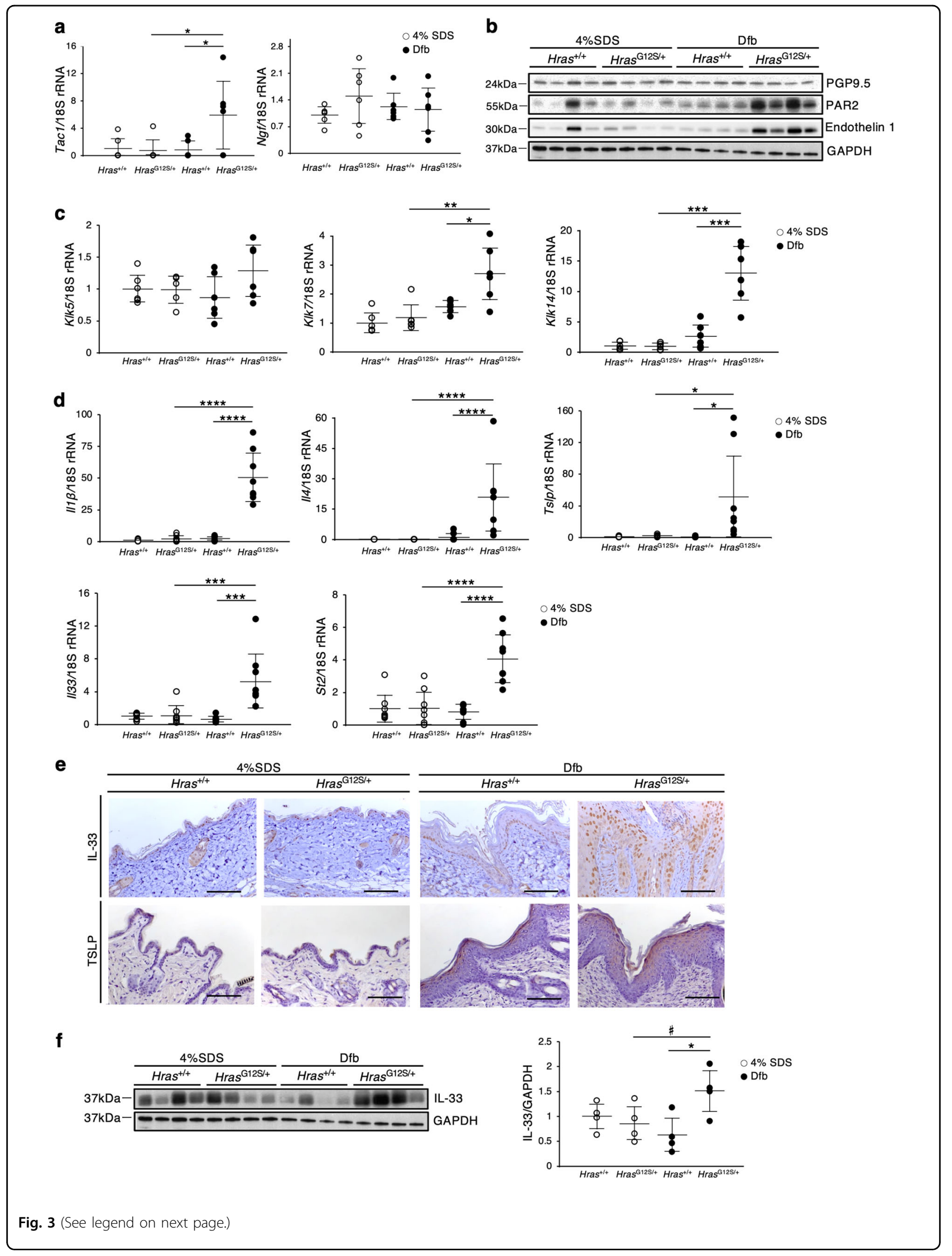


(see figure on previous page)

Fig. 3 Expression of itch-associated factors and inflammatory cytokines is enhanced in Dfb-induced skin lesions in Hras ${ }^{G 125 /+}$ mice. a, c, d Relative mRNA expression related to neuronal factors (a: Tac1 and Ngf), skin proteases (c: Klk5, Klk7, and Klk14), and inflammation (d: II1 1114, Ts/p, II33, and St2) in the dorsal skin. mRNA levels were normalized to those of $18 \mathrm{~s} r$ RNA ( $n=8$ per group). b, $\mathbf{f}$ Protein extracts from dorsal skin were immunoblotted with anti-PGP9.5, anti-PAR2, anti-Endothelin 1, and anti-IL-33 antibody ( $n=4$ in each group). GAPDH, same data as in Fig. 2 d. f Band intensities were quantified and compared among the four groups. Expression levels were normalized to GAPDH. e Immunohistochemistry of IL-33 and TSLP. Scale bars: $100 \mu \mathrm{m}$. Data are presented as mean \pm SD. Significance was analyzed by one-way ANOVA and the Tukey - Kramer method. ${ }^{*} P<$ $0.05,{ }^{* *} P<0.01,{ }^{* *} P<0.001$, and ${ }^{* * *} P<0.0001 .{ }^{*} P<0.05$, two-tailed Student's $t$ test.

AD-like skin lesions under conditions of Dfb exposure. The levels of IL-1 $\beta$ and epithelial cell-derived cytokines, IL-33 and TSLP, were also increased in Dfb-treated Hras $^{\text {G12S/+ }}$ mice. In addition, an increased production of IL-1 $\beta$, IL-4, and IL-33, as well as inflammatory cells, basophils, and ILC2s, was observed in the dorsal skin of $\mathrm{Hras}^{\mathrm{G} 12 \mathrm{~S} /+}$ mice before the development of AD-like skin lesions. Analysis of the underlying mechanism revealed that Dfb-stimulated keratinocytes in $\mathrm{Hras}^{\mathrm{GI2S} /+}$ mice induced IL-33 production, while, in naive $\mathrm{CD} 4^{+} \mathrm{T}$ cells from the spleen, the Th2 immune response was comparable between $\mathrm{Hras}^{+/+}$and $\mathrm{Hras}^{\mathrm{G12S} /+}$ mice. Finally, the inhibition of ERK activation by PD0325901 treatment ameliorated the AD-like skin lesions and IL-33 production. Together, these data indicate that germline Hras G12S activating mutation causes AD-like skin lesions via the ERK/IL-33 axis (Fig. 8).

In the present study, after repeated stimulation with $\mathrm{Dfb}, \mathrm{Hras}^{\mathrm{G} 12 \mathrm{~S} /+}$ mice showed hyperproliferation of $\mathrm{p}-$ ERK-positive epidermal cells and increased IL-33 expression in the dorsal skin. Increased IL-33 expression was also observed in primary epidermal keratinocytes from $\mathrm{Hras}^{\mathrm{G12S} /+}$ mice after Dfb stimulation, which is similar to the reports that the activation of RAS/MAPK signaling was associated with increased IL-33 expression in cancer cells ${ }^{29,30}$. Recently, IL-33 was found to induce the Th2 inflammatory response in allergic diseases, especially $A D^{31}$. Excess IL-33 is also associated with skin barrier dysfunction and ILC2 functions, which is partially regulated by the RAS/MAPK signaling pathway ${ }^{32,33}$. Epithelial-specific IL-33 transgenic mice have been found to develop AD-like dermatitis, including acanthosis, pruritus, increased IgE serum levels, reduced claudin-1 expression, and increased production of eosinophils, mast cells, and ILCs ${ }^{33,34}$. Of note, IL-33 and its receptor, ST-2, are highly expressed in the skin-derived ILC2s of AD patients and lung ILC2s of patients with allergic airway diseases, respectively ${ }^{35,36}$. Importantly, consistent with the phenotype of IL-33 transgenic mice and AD patients, Dfbtreated $\mathrm{Hras}^{\mathrm{Gl} S \mathrm{~S} /+}$ mice showed AD-like skin lesions, reduced claudin-1 expression, increased IL-33 expression, hyperproliferation of p-ERK-positive epidermal cells, and increased ILC2 production. Collectively, excess IL-33 could lead to ERK activation, resulting in an increase of ILC2s and impaired skin barrier (Fig. 8).
The pathogenesis of skin lesions observed in Costello syndrome includes dermal connective tissue abnormalities (cutis laxa and deep palmer and plantar creases), hyperproliferative skin disease (palmoplantar keratoderma, cutaneous papilloma, and acanthosis nigricans), and inflammatory skin abnormalities (sensitive skin, eczema, and pruritus). A previous study showed that, in the skin fibroblasts of Costello syndrome, elastic fibers were not assembled due to a functional deficiency of the elastin-binding protein as a result of an unusual accumulation of chondroitin sulfate-bearing proteoglycans $^{37,38}$. Regarding the hyperproliferative skin lesions, it has been reported that the root cause of papillomas, hyperkeratosis, and epidermal hyperplasia, such as psoriasis, is the activation of the RAS-MAPK pathway ${ }^{39-42}$. However, the pathophysiological mechanism of inflammatory skin abnormalities in Costello syndrome remains unclear. In the present study, Dfb-treated $\mathrm{Hras}^{\mathrm{G12S} /+}$ mice displayed pruritus and eczema. Recently, mice with epidermis-specific BRAF/RAF1 deficient also showed ADlike dermatitis, which is characterized by increased serum IgE levels and a Th2 response ${ }^{43}$. The elevated IgE levels have not been systematically examined or reported in Costello syndrome patients. However, it is possible that the allergic reaction stimulated by house dust mites could be involved in the development of inflammatory skin abnormalities in Costello syndrome patients, including sensitive skin, pruritus, and eczema.

At present, acitretin has been reported to treat palmoplantar keratosis in patients with Costello and CFC syndrome $^{44,45}$. Several reports have demonstrated that MEK inhibitors improve HRAS-driven tumorigenesis ${ }^{46}$, impaired enamel formation in the teeth ${ }^{27}$, and long-term depression in the hippocampus in Hras G12V knock-in mice $^{28}$, as well as hyperkeratosis and hyperplasia in the forestomach of $\mathrm{Braf}^{\mathrm{Q} 241 R /+}$ mice $^{26}$. In the present study, PD0325901 treatment of the AD-like skin lesions in $\mathrm{Hras}^{\mathrm{G12S} /+}$ mice was found to reverse these lesions by reducing hyperproliferation of p-ERK-positive epidermal cells and the production of inflammatory cells and cytokines, including IL-1 $\beta$, IL-4, and IL-33. Treatment with U0126, an MEK inhibitor, in human keratinocytes, has also been found to restore the reduced expression levels of claudin-1 and filaggrin, and increase ERK activation through excess IL-33 33,47 . Indeed, reduced claudin-1 


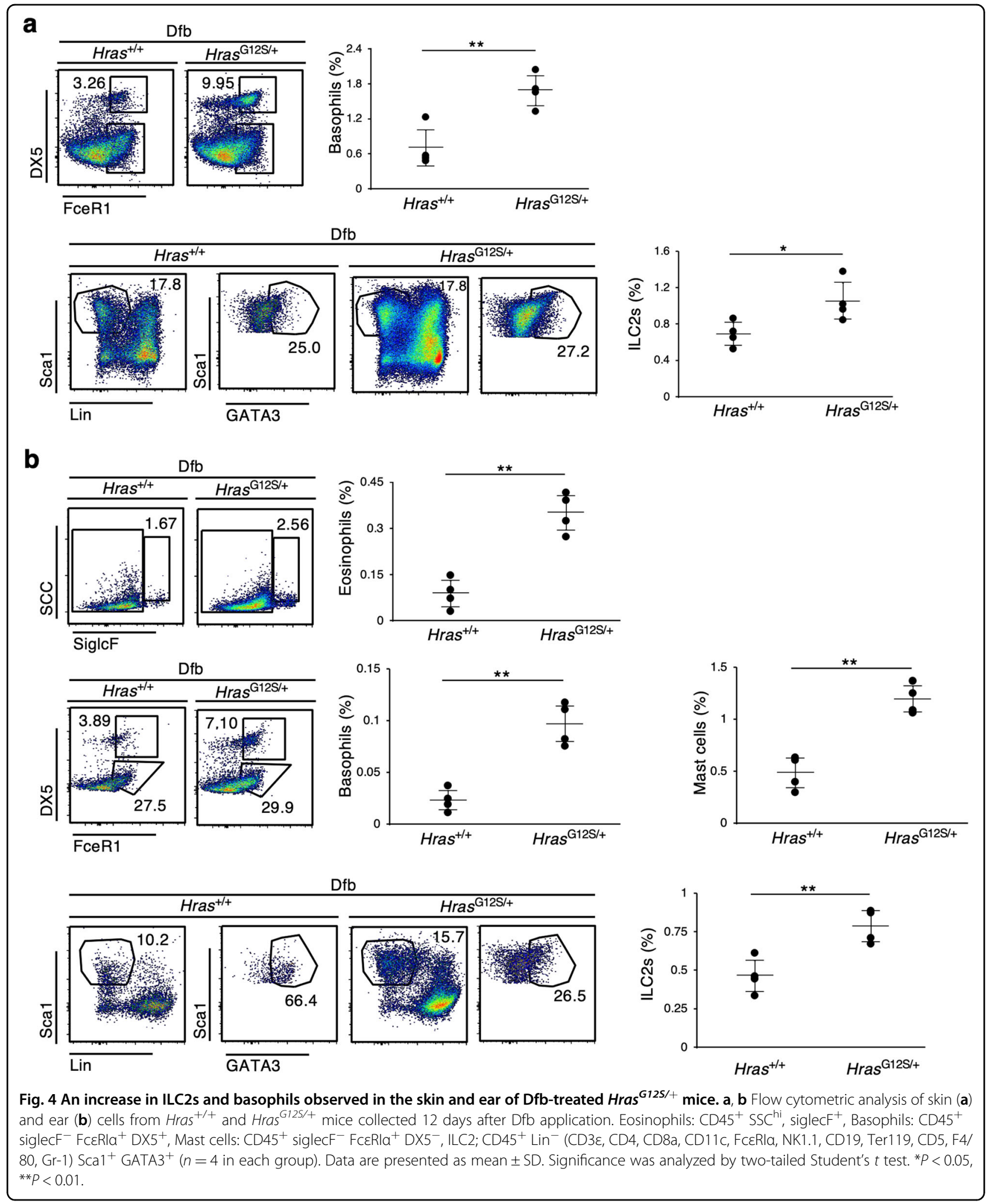

expression was improved in Dfb-treated Hras ${ }^{G 12 S /+}$ mice after PD0325901 treatment. Recently, hypertrophic cardiomyopathy in Noonan syndrome patients were treated by MEK inhibitor ${ }^{48}$. So, MEK inhibitors could be effective in patients with RASopathies. The most common side effect of trametinib (MEK inhibitor) in human patients is 


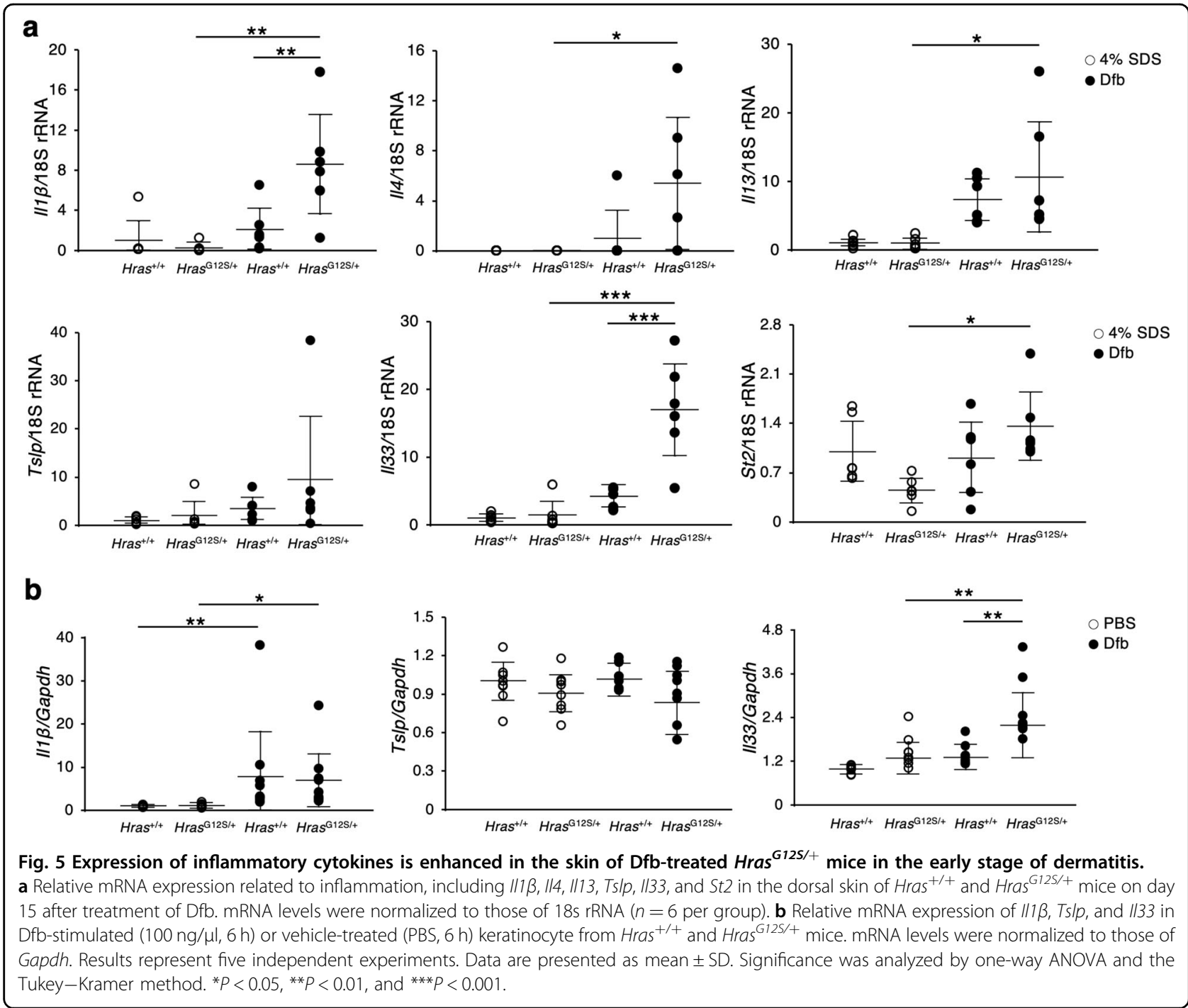

skin rush, and common toxicity associated with vemurafenib (BRAF inhibitor) is cutaneous abnormalities such as keratoacanthoma and squamous cell carcinoma by the mechanism of paradoxical MAPK pathway activation ${ }^{49}$. Therefore, the balance of RAS/MAPK signaling plays an important role in the emersion of skin abnormalities. Adjusting dosage of MEK inhibitors may be effective on skin lesions of patients with Costello syndrome.

Here, Dfb-treated Hras ${ }^{\text {G12S/+ }}$ mice exhibited increased IL-33 expression through hyperproliferation of p-ERKpositive epidermal cells. Additionally, we show that PD0325901 treatment ameliorated the AD-like skin lesions in $\mathrm{Hras}^{\mathrm{G12S} /+}$ mice under conditions of exposure to Dfb. Thus, it will be interesting to investigate whether treatment with IL-33 antibody reduces the AD-like skin lesions in $\mathrm{Hras}^{\mathrm{G12S} /+}$ mice. Our findings provide additional perspective that $\mathrm{Hras}^{\mathrm{G} 12 \mathrm{~S} /+}$ mice will serve as a valuable model to study pathophysiology and potential therapeutic approaches in AD.

\section{Materials and methods \\ Mice}

Hras $^{\text {G12S/+ }}$ mice on a C57BL/6J background have been described previously ${ }^{13}$. Male mice were analyzed in this study.

\section{Genotyping}

The genomic DNA was extracted from the tail tissue using a Maxwell 16 Mouse Tail DNA Purification Kit (Promega, Madison, WI, USA) or the alkaline lysis method. For the alkaline lysis method, a small piece of each tail $(2 \mathrm{~mm})$ was incubated in $50 \mathrm{mM} \mathrm{NaOH}$ for $20 \mathrm{~min}$ at $95^{\circ} \mathrm{C}$. After the addition of $1 \mathrm{M}$ Tris- $\mathrm{HCl}$ (pH 8.0), the extracts were used for PCR. Genotyping of 


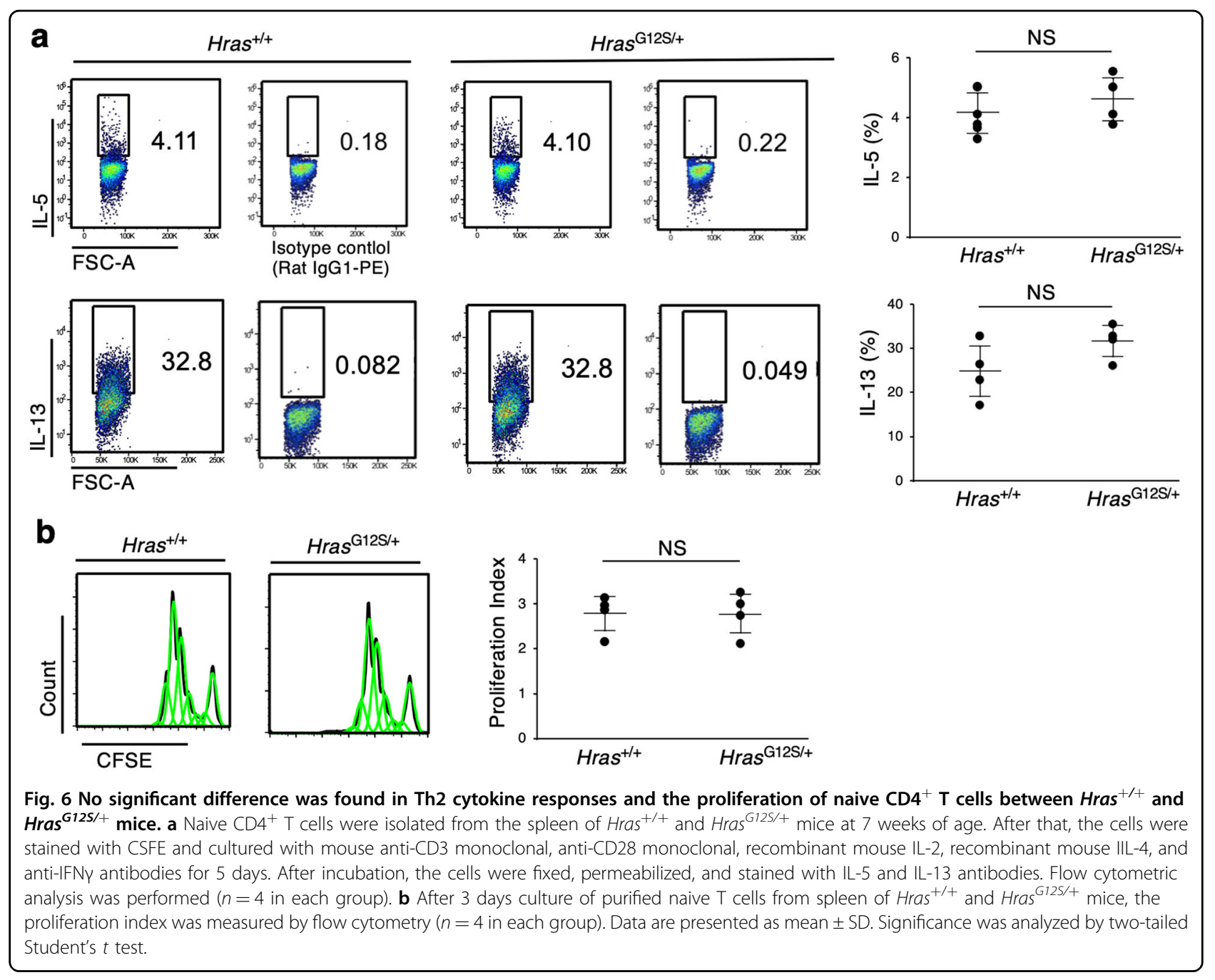

Hras $^{+/+}$and Hras ${ }^{\text {G12S/+ }}$ mice was performed by PCR using KOD FX Neo (TOYOBO, Osaka, Japan). The primers used for PCR have been described previously ${ }^{13,50}$.

\section{Induction of dermatitis}

Atopic dermatitis-like skin lesions were induced in male mice at 9 weeks of age, according to the manufacturer's instructions. The mice were anesthetized with isoflurane and their dorsal hair was removed using an electric clipper (2000AD; Natsume Seisakusho, Tokyo, Japan). For sensitization, $100 \mathrm{mg}$ of Biostir AD (Biostir Inc, Kobe, Japan), an ointment of Dfb extract, was applied to the shaved dorsal skin and ears. Three or four days later, hair growth was removed with an electric clipper, and $150 \mu \mathrm{l}$ of $4 \%$ SDS (Sigma-Aldrich, St. Louis, MO, USA) was applied to the shaved dorsal skin and ears to disrupt the skin barrier. After $2 \mathrm{~h}, 100 \mathrm{mg}$ of Biostir AD was applied to their shaved dorsal skin and ears to induce AD-like skin lesions. These procedures were repeated twice a week for 25 days. The mice were sacrificed on day 32 to collect skin and ear samples (Supplementary Fig. 2a). To assess the effect of $\mathrm{Dfb}$ ointment to $\mathrm{Hras}^{+/+}$and $\mathrm{Hras}^{\mathrm{G12S} /+}$ mice, they were randomly divided into four groups (4\% SDS-treated $\mathrm{Hras}^{+/+}$, 4\% SDS-treated $\mathrm{Hras}^{\mathrm{GI2S} /+}$, Dfb-treated $\mathrm{Hras}^{+/+}$, and Dfb-treated Hras $^{\text {G12S/+ }}$ ) using single blinding test.

\section{Evaluation of dermatitis and ear thickness}

The dermatitis scores were evaluated twice a week according to the development of four symptoms: erythema/hemorrhage of dorsal skin, scarring/dryness of dorsal skin, edema of ear, and excoriation/erosion of $\mathrm{ear}^{51}$. The total dermatitis score (maximum score: 12) was defined as the sum of individual scores (none: 0 , mild: 1 , moderate: 2 , severe: 3 ) for each symptom (Supplementary Table 1). Ear thickness was measured with a digimatic micrometer (CLM1-15QM; Mitutoyo, Kanagawa, Japan).

\section{Measurement of scratching behavior}

On day 28 , scratching behavior was monitored by video (GZ-HM890; JVC, Kanagawa, Japan) for $30 \mathrm{~min}$. The 
a

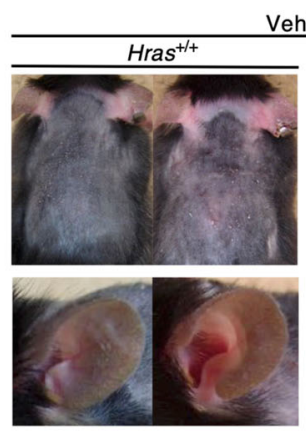

b

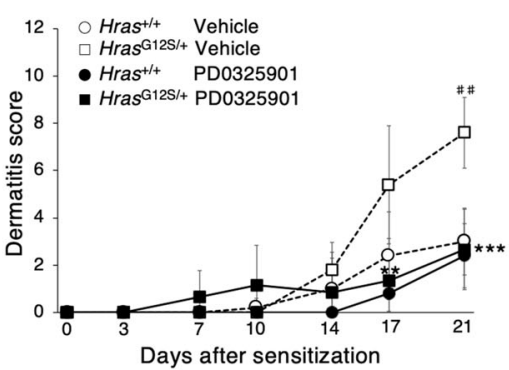

C
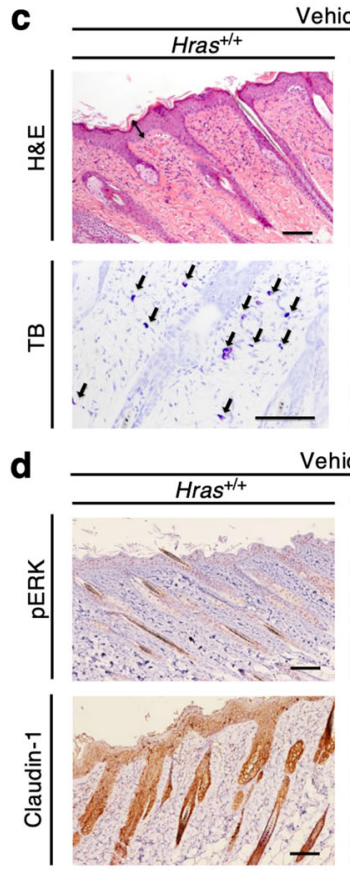

Vehicle
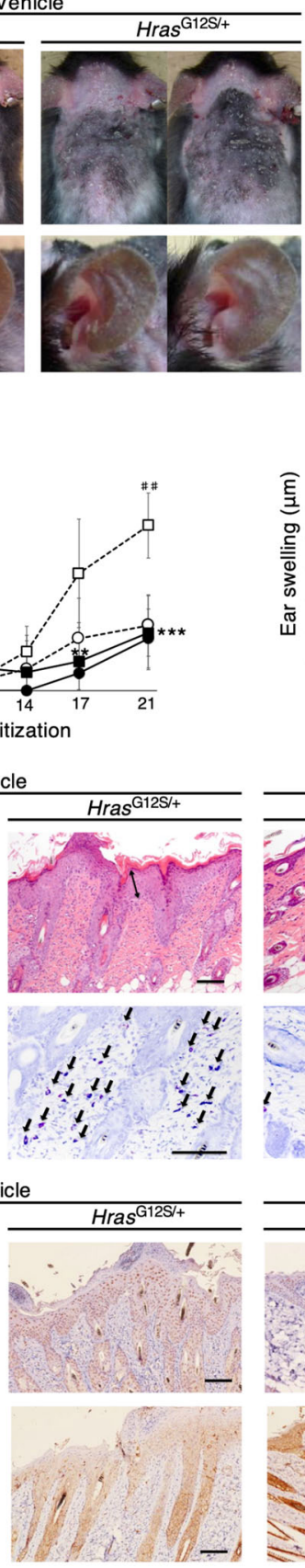

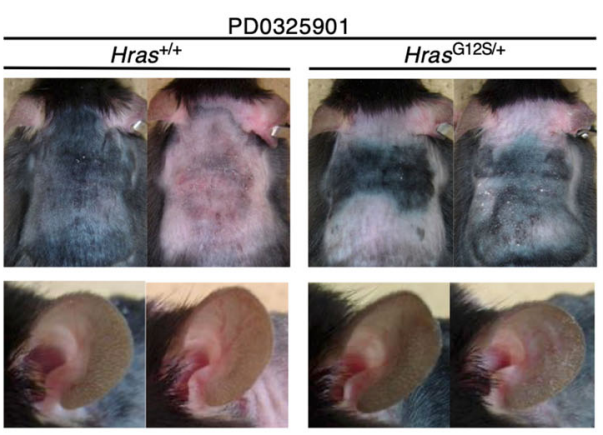

PD0325901
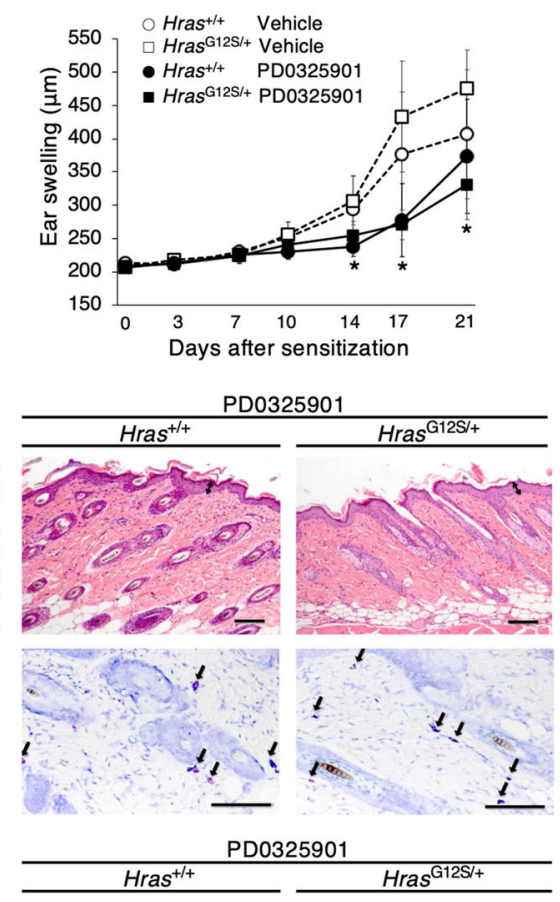

e
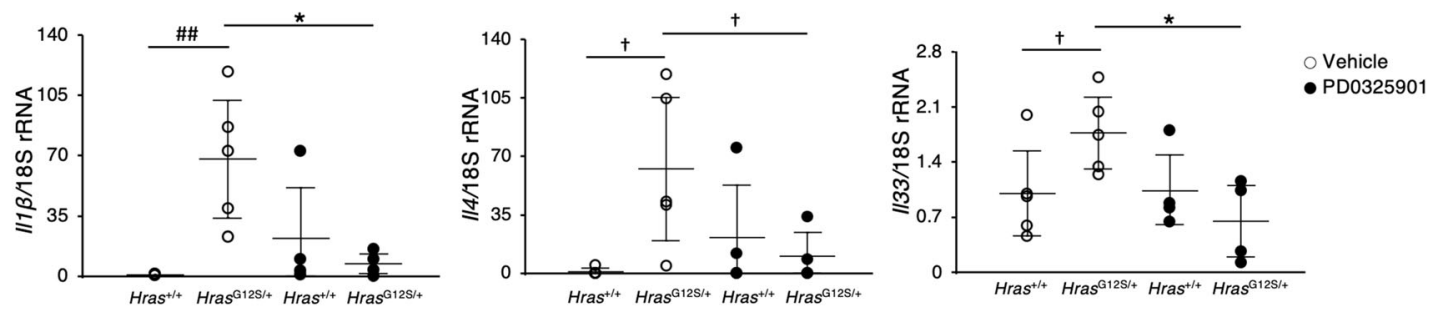

Fig. 7 (See legend on next page.) 
(see figure on previous page)

Fig. 7 MEK inhibitor reduces the clinical severity of dermatitis in Dfb-stimulated Hras $^{\text {G12S/+ }}$ mice. $\mathbf{a}$, b Gross appearances, dermatitis score, and ear thickness in vehicle (saline) or PD0325901-treated $\mathrm{Hras}^{+/+}$and $\mathrm{Hras}^{\mathrm{G}}{ }^{125 /+}$ mice after 10 days of daily injections $(n=5$ per group). All of the mice in these figures were treated with Dfb. The open circle and open square show vehicle group (without MEKi, with same amount of saline). c Skin tissue stained with H\&E and TB in $\mathrm{Hras}^{+/+}$and Hras ${ }^{\mathrm{G} / 2 S /+}$ mice with PD0325901 or vehicle treatment ( $n=5$ per group). d Immunohistochemistry of p-ERK and claudin-1 in skin. $\mathbf{c}$, $\mathbf{d}$ Scale bars: $100 \mu \mathrm{m}$. e Relative mRNA expression of $\|1 \beta\|$,4 , and 1133 in dorsal skin. mRNA levels were normalized to those of 18s rRNA (vehicle group: $n=5$; PD0325901 group: $n=4$ ). Data are presented as mean \pm SD. Significance was analyzed by one-way ANOVA and the Tukey-Kramer method. ${ }^{*} P<0.05{ }^{* *} P<0.01$, and ${ }^{* * *} P<0.001$ Hras $^{G 12 S /+}$ PD0325901 vs Hras ${ }^{G 12 S /+}$ vehicle; ${ }^{\# \#} P<0.01$, Hras ${ }^{G 12 S /+}$ vehicle vs Hras ${ }^{+/+}$ vehicle. ${ }^{\dagger} P<0.05$, one-tailed Student's $t$ test.

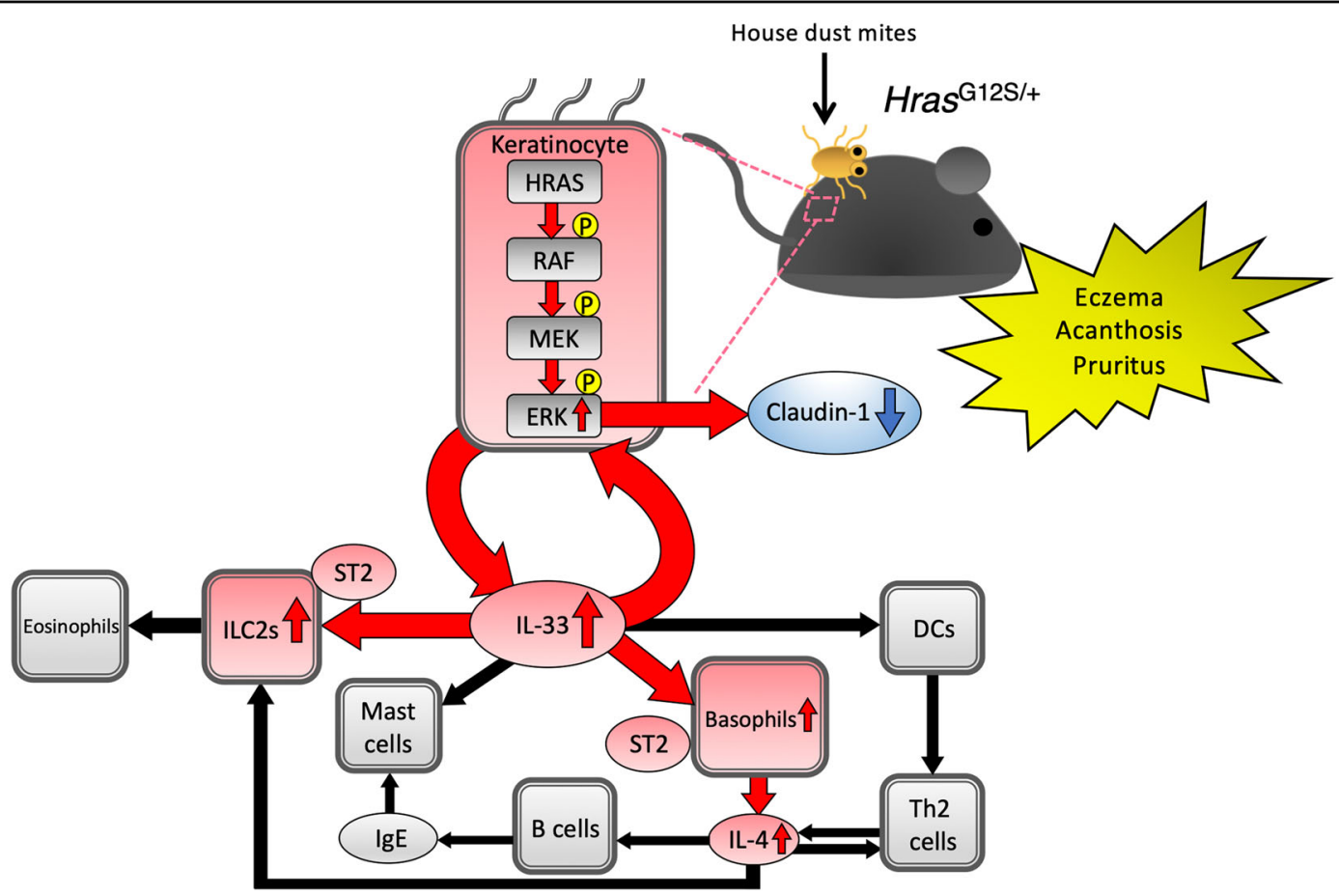

Fig. 8 Germline $\operatorname{Hras}^{G 12 S}$ mutation causes AD-like skin lesions via ERK/LL-33 axis. Exposure to Dfb allergen induces AD-like skin lesions, including eczema, acanthosis, and pruritus in $\mathrm{Hras}^{\text {G12S/+ }}$ mice. Dfb-treated Hras ${ }^{\text {GI2S/+ }}$ keratinocytes show increased IL-33 expression through hyperproliferation of p-ERK-positive epidermal cells. Excess IL-33 activates basophil- and ILC2-containing ST2 receptors. These activated immune cells induce the production of type-2 inflammatory cytokines, such as IL-4. Furthermore, excess IL-33 can activate ERK signaling, resulting in reduced claudin-1 expression and skin barrier dysfunction. DC dendritic cells.

number of scratching bouts was assessed by replaying the video. Each incidence of scratching behavior was defined as rubbing of ears and dorsal skin with forepaws, hind paws, and mouth.

\section{Histology and immunohistochemistry}

The dorsal skins were fixed in $10 \%$ neutral buffered formalin for paraffin-embedded specimen and $4 \%$ paraformaldehyde for frozen specimen. Embedded tissues were sectioned at $3 \mu \mathrm{m}$ (paraffin-embedded specimens) or $8 \mu \mathrm{m}$ (frozen specimens). Paraffin-embedded specimens were stained with hematoxylin and eosin (H\&E) and toluidine blue (TB). Epidermal thickness was measured in five randomly selected areas $(900 \times 700 \mu \mathrm{m})$ of each H\&E-stained sample. Mast cells were counted in ten randomly selected areas $(450 \times 350 \mu \mathrm{m})$ of each TBstained sample. For immunohistochemistry, the paraffinembedded sections were deparaffinized using xylene and rehydrated with ethanol. Frozen specimens were dried sufficiently with a dryer. Antigens were activated using a Histofine simple stain kit (Nichirei Bio Sciences, Tokyo, Japan). The antibodies used are described in Supplementary Table 2. Signals were visualized with a DAB Substrate Kit (Nichirei Bio Sciences). Sections were counterstained with hematoxylin. p-ERK immunostained area/epidermis (\%) was measured in five randomly 
selected areas $(900 \times 700 \mu \mathrm{m})$ of each p-ERK-stained sample.

\section{Quantitative reverse transcription-PCR}

Total RNA extraction and purification of keratinocytes was performed according to the standard procedures using an RNeasy Mini Kit (Qiagen, Hilden, Germany) and QIAshredder (Qiagen). The extraction and purification of the total RNA from the dorsal skin and cDNA synthesis were performed as previously described ${ }^{26}$. Quantitative real-time PCR was performed using THUNDERBIRD SYBR qPCR MIX (TOYOBO) in a StepOnePlus (Thermo Fisher Scientific, Waltham, MA, USA). The amplification primers are described in Supplementary Table 3. Each sample was run in duplicate.

\section{Western blotting}

Skin tissue was homogenized in lysis buffer $(10 \mathrm{mM}$ Tris$\mathrm{HCl} \mathrm{pH} 7.5$ and 1\% SDS) containing phosphatase and protease inhibitor (P5726 and P8340; Sigma-Aldrich). Supernatants were collected after centrifugation and the protein concentration was determined using a Bio-Rad Protein Assay (Bio-Rad Laboratories, Hercules, CA). Western blot analyses were performed as previously described ${ }^{26}$. Briefly, the proteins were transferred onto nitrocellulose membranes and blocked with $5 \%$ non-fat milk in Tris-buffered saline with Tween-20 (10 mmol/L Tris-HCl, $\mathrm{pH} 8.0,150 \mathrm{mmol} / \mathrm{L}$ $\mathrm{NaCl}$, and $0.1 \%$ Tween-20) for $1 \mathrm{~h}$ at room temperature. The membranes were incubated overnight at $4{ }^{\circ} \mathrm{C}$ with the antibodies described in Supplementary Table 2. All membranes were visualized using the Western Lightning ECL Plus Kit (PerkinElmer, Waltham, MA, USA). The band intensities were quantified using NIH ImageJ software.

\section{ELISA}

Serum IgE was determined using LBIS Mouse IgE ELISA Kit (FUJIFILM Wako Shibayagi, Gunma, Japan), according to the manufacturers' instructions.

\section{Skin and ear immune cell preparation and flow cytometry}

The hair on the dorsal skin was shaved off before removing the subcutaneous fat and connective tissue. The skin and ear were cut into pieces and incubated in RPMI 1640 (FUJIFILM Wako, Osaka, Japan) containing 10\% fetal calf serum (FCS), Collagenase (C5138; SigmaAldrich), Dispase (17105-04; Gibco BRL, Palo Alto, CA), DNase I, and Hyaluronidase (Sigma-Aldrich) for $90 \mathrm{~min}$ to isolate single-cell suspension ${ }^{52}$. After incubation in 2.4G2 (130-092-575; Miltenyi Biotec, Auburn, CA) as an Fc-blocking reagent, cells were stained with the antibodies described in Supplementary Table 2. Flow cytometry data were acquired by Spectral Analyzer (SP6800; SONY, Tokyo, Japan) and analyzed with FlowJo (Becton, Dickinson and Company, USA).

\section{Spleen and LN immune cell preparation and flow cytometry}

The spleen and inguinal LN from mice were cut into pieces and incubated in ACK lysis buffer $\left(150 \mathrm{mM} \mathrm{NH}_{4} \mathrm{Cl}\right.$, $10 \mathrm{mM} \mathrm{KHCO}, 0.1 \mathrm{mM}$ ethylenediaminetetraacetic acid $2 \mathrm{Na}, \mathrm{pH}$ 7.2) for $2 \mathrm{~min}$. After incubation in 2.4G2 (Miltenyi Biotec) as an Fc-blocking reagent, the cells were stained with the antibodies described in Supplementary Table 2. The flow cytometry data were acquired by BD FACSCANTO II (BD Bioscience, Franklin Lakes, New Jersey) and analyzed with FlowJo (Becton).

\section{Spleen immune cell preparation and naive $\mathrm{CD} 4^{+} \mathrm{T}$-cell sorting assays}

Mouse naive $\mathrm{CD} 4^{+} \mathrm{T}$ cells were isolated from the spleen by magnetic sorting according to standard procedures using a naive $\mathrm{CD} 4^{+} \mathrm{T}$-cell isolation kit (Miltenyi Biotec). CFSE (C1157; Invitrogen, San Diego, CA)-stained cells were suspended in RPMI 1640 medium containing 10\% FCS. The cell suspensions were cultured and stimulated with plate-bound mouse anti-CD3 and anti-CD28 monoclonal antibodies, recombinant mouse IL-2, IL-4, and anti-IFNy antibodies for 5 days in a $37^{\circ} \mathrm{C}, 5 \% \mathrm{CO}_{2}$ incubator. The cell suspensions were re-stimulated with phorbol 12-myristate 13-acetate (Sigma-Aldrich), ionomycin (Sigma-Aldrich), and GolgiPlug (BD Bioscience) for $3 \mathrm{~h}$. Cells were fixed and permeabilized with fixation/ permeabilization solution (BD Bioscience) and stained with IL-5 and IL-13 antibodies. After 3 days of culturing the purified naive $\mathrm{T}$ cells, the proliferation index was determined by flow cytometry. The flow cytometry data were acquired by Spectral Analyzer (SONY) and analyzed with FlowJo (Becton).

\section{Cell culture and stimulation}

Primary epidermal keratinocytes were isolated from newborn mice (0- or 1-day-old) and cultured according to recommended protocol using a CnT-PR (CELLnTEC, Bern, Switzerland), CnT-GAB10 (CELLnTEC), Dispase II (Gibco BRL), and TrypLE Express Enzyme (Gibco BRL). Briefly, the skin was peeled from the neonates and incubated in CnT-PR with CnT-GAB10 $(10 \mu \mathrm{g} / \mathrm{mL}$ gentamycin and $0.5 \mu \mathrm{g} / \mathrm{mL}$ amphotericin B) and $12.5 \mathrm{U} / \mathrm{mL}$ dispase for $16 \mathrm{~h}$ at $4{ }^{\circ} \mathrm{C}$. The epidermis was separated from the dermis and incubated in TrypLE Express Enzyme for 20-30 min at room temperature. The cells were separated from the epidermal sheet, seeded at a density of $4 \times 10^{4}$ cells $/ \mathrm{cm}^{2}$ in CnT-PR medium, and cultured in a $37^{\circ} \mathrm{C}, 5 \% \mathrm{CO}_{2}$ incubator. Medium change was performed after $24 \mathrm{~h}$ and 4 days after seeding. After 5 days of culture, $100 \mathrm{ng} / \mathrm{mL}$ of mite dermatophagoides farina crude extract (LSL, Tokyo, Japan) in phosphate buffered saline (PBS) was added to the culture medium. After $6 \mathrm{~h}$ of incubation, the cells were collected for quantitative reverse transcription-PCR analysis. 


\section{Mouse treatment}

PD0325901 (Sigma-Aldrich) was dissolved in ethanol at a concentration of $5 \mathrm{mg} / \mathrm{mL}$ and prepared in saline at a concentration of $0.125 \mathrm{mg} / \mathrm{mL}$. PD0325901 $(1.0 \mathrm{mg} / \mathrm{kg} /$ body weight) was intraperitoneal injected into anesthetized mice daily from days 12 to 21 after the start of Dfb application (Supplementary Fig. 5a).

\section{Statistical analysis}

All data are presented as mean \pm standard deviation (SD). Statistical analyses were performed using Student's $t$ test for comparisons between two groups. Comparisons among four groups were performed using one-way ANOVA and the Tukey-Kramer method. All data were analyzed using JMP Pro 14 software (SAS, Cary, NC). $P$ value below 0.05 was considered statistically significant.

\section{Study approval}

All animal studies were approved by the Animal Care and Use Committees of Tohoku University.

\section{Acknowledgements}

We wish to thank Riyo Takahashi, Kumi Kato, and Yoko Tateda for technical assistance. We would also like to acknowledge the support of the Biomedical Research Core of the Tohoku University Graduate School of Medicine. This work was supported by Japan Agency for Medical Research and Development under Grant to Y. A. (JP18ek0109241), by the Japan Society for the Promotion of Science (JSPS) KAKENHI Grant Number $17 \mathrm{H} 04223$ to Y. A., and by JSPS KAKENHI Grant Number 18 K07811 to S.-i.l.

\section{Author details \\ 'Department of Medical Genetics, Tohoku University Graduate School of Medicine, Sendai, Japan. ${ }^{2}$ Department of Pediatrics, Tohoku University Graduate School of Medicine, Sendai, Japan. ${ }^{3}$ Department of Microbiology and Immunology, Tohoku University Graduate School of Medicine, Sendai, Japan. ${ }^{4}$ Department of Organ Anatomy, Tohoku University Graduate School of Medicine, Sendai, Japan. ${ }^{5}$ Department of Dermatology, Tohoku University Graduate School of Medicine, Sendai, Japan}

\section{Data availability}

The authors declare that all other data of this study are available from the corresponding author upon reasonable request.

\section{Conflict of interest}

The authors declare that they have no conflict of interest.

\section{Publisher's note}

Springer Nature remains neutral with regard to jurisdictional claims in published maps and institutional affiliations.

Supplementary Information accompanies this paper at (https://doi.org/ 10.1038/s41419-020-02845-8).

Received: 18 March 2020 Revised: 29 July 2020 Accepted: 30 July 2020 Published online: 13 August 2020

\footnotetext{
References

1. Blanpain, C.\& Fuchs, E. Epidermal homeostasis: a balancing act of stem cells in the skin. Nat. Rev. Mol. Cell Biol. 10, 207-217 (2009).
}

2. Malumbres, M. \& Barbacid, M. RAS oncogenes: the first 30 years. Nat. Rev. Cancer 3, 459-465 (2003).

3. Takai, Y., Sasaki, T. \& Matozaki, T. Small GTP-binding proteins. Physiol. Rev. 81, 153-208 (2001)

4. Kern, F., Niault, T. \& Baccarini, M. Ras and Raf pathways in epidermis development and carcinogenesis. Br. J. Cancer 104, 229-234 (2011).

5. Ratushny, V., Gober, M. D., Hick, R., Ridky, T. W. \& Seykora, J. T. From keratinocyte to cancer: the pathogenesis and modeling of cutaneous squamous cell carcinoma. J. Clin. Invest. 122, 464-472 (2012).

6. Chu, E. Y. et al. Diverse cutaneous side effects associated with BRAF inhibitor therapy: a clinicopathologic study. J. Am. Acad. Dermatol. 67, 1265-1272 (2012).

7. Rauen, K. A. The RASopathies. Annu. Rev. Genomics Hum. Genet. 14, 355-369 (2013).

8. Tidyman, W. E. \& Rauen, K. A. The RASopathies: developmental syndromes of Ras/MAPK pathway dysregulation. Curr. Opin. Genet. Dev. 19, 230-236 (2009).

9. Aoki, Y., Niihori, T., Inoue, S. \& Matsubara, Y. Recent advances in RASopathies. J. Hum. Genet. 61, 33-39 (2016).

10. Gripp, K. W. et al. Costello syndrome: clinical phenotype, genotype, and management guidelines. Am. J. Med. Genet. A 179, 1725-1744 (2019).

11. Aoki, Y. et al. Germline mutations in HRAS proto-oncogene cause Costello syndrome. Nat. Genet. 37, 1038-1040 (2005).

12. Gripp, K. W. et al. HRAS mutation analysis in Costello syndrome: genotype and phenotype correlation. Am. J. Med. Genet. A 140, 1-7 (2006).

13. Oba, D. et al. Mice with an oncogenic HRAS mutation are resistant to high-fat diet-induced obesity and exhibit impaired hepatic energy homeostasis. EBioMedicine 27, 138-150 (2018).

14. Thyssen, J. P. \& Kezic, S. Causes of epidermal filaggrin reduction and their role in the pathogenesis of atopic dermatitis. J. Allergy Clin. Immunol. 134, 792-799 (2014).

15. De Benedetto, A. et al. Tight junction defects in patients with atopic dermatitis J. Allergy Clin. Immunol. 127, 773-786.e771-777 (2011).

16. Tokumasu, R. et al. Dose-dependent role of claudin-1 in vivo in orchestrating features of atopic dermatitis. Proc. Natl Acad. Sci. USA 113, E4061-E4068 (2016).

17. Tsujii, K., Andoh, T., Ui, H., Lee, J.-B. \& Kuraishi, Y. Involvement of tryptase and proteinase-activated receptor- 2 in spontaneous itch-associated response in mice with atopy-like dermatitis. J. Pharmacol. Sci. 109, 388-395 (2009).

18. Kido-Nakahara, M. et al. Neural peptidase endothelin-converting enzyme 1 regulates endothelin 1 -induced pruritus. J. Clin. Invest. 124 2683-2695 (2014)

19. Yamada, Y. \& Matsumoto, T. House dust mites induce production of endothelin-1 and matrix metalloproteinase-9 in keratinocytes via proteinaseactivated receptor-2 activation. Int. Arch. Allergy Immunol. 173, 84-92 (2017).

20. Stefansson, $\mathrm{K}$. et al. Activation of proteinase-activated receptor-2 by human kallikrein-related peptidases. J. Invest. Dermatol. 128, 18-25 (2008).

21. Schmitz, J. et al. IL-33, an interleukin-1-like cytokine that signals via the IL-1 receptor-related protein ST2 and induces T helper type 2-associated cytokines. Immunity 23, 479-490 (2005).

22. Kabashima, K. New concept of the pathogenesis of atopic dermatitis: interplay among the barrier, allergy, and pruritus as a trinity. J. Dermatol. Sci. 70, 3-11 (2013).

23. Furue, M. et al. Atopic dermatitis: immune deviation, barrier dysfunction, lgE autoreactivity and new therapies. Allergol. Int. 66, 398-403 (2017).

24. Schuhmacher, A. J. et al. A mouse model for Costello syndrome reveals an Ang II-mediated hypertensive condition. J. Clin. Invest. 118, 2169-2179 (2008).

25. Leon, J., Guerrero, I. \& Pellicer, A. Differential expression of the ras gene family in mice. Mol. Cell Biol. 7, 1535-1540 (1987).

26. Inoue, S. I. et al. Activated Braf induces esophageal dilation and gastric epithelial hyperplasia in mice. Hum. Mol. Genet. 26, 4715-4727 (2017).

27. Goodwin, A. F. et al. Abnormal Ras signaling in Costello syndrome (CS) negatively regulates enamel formation. Hum. Mol. Genet. 23, 682-692 (2014).

28. Schreiber, J. et al. Mechanisms underlying cognitive deficits in a mouse model for Costello Syndrome are distinct from other RASopathy mouse models. Sci. Rep. 7, 1256 (2017).

29. Nakagawa, $\mathrm{H}$. et al. Biliary epithelial injury-induced regenerative response by IL-33 promotes cholangiocarcinogenesis from peribiliary glands. Proc. Natl Acad. Sci. USA 114, E3806-E3815 (2017).

30. Hong, J., Kim, S. \& Lin, P. C. Interleukin-33 and ST2 signaling in tumor microenvironment. J. Interferon Cytokine Res. 39, 61-71 (2019). 
31. Imai, Y. Interleukin-33 in atopic dermatitis. J. Dermatol. Sci. 96, 2-7 (2019).

32. Nygaard, U. et al. The "alarmins" HMBG1 and IL-33 downregulate structural skin barrier proteins and impair epidermal growth. Acta Derm. Venereol. 97, 305-312 (2017)

33. Ryu, W. I. et al. IL-33 down-regulates CLDN1 expression through the ERK STAT3 pathway in keratinocytes. J. Dermatol. Sci. 90, 313-322 (2018).

34. Imai, Y. et al. Skin-specific expression of IL-33 activates group 2 innate lymphoid cells and elicits atopic dermatitis-like inflammation in mice. Proc. Natl Acad. Sci. USA 110, 13921-13926 (2013)

35. Salimi, M. et al. A role for IL-25 and IL-33-driven type-2 innate lymphoid cells in atopic dermatitis. J. Exp. Med. 210, 2939-2950 (2013).

36. Drake, L. Y. \& Kita, H. IL-33: biological properties, functions, and roles in airway disease. Immunol. Rev. 278, 173-184 (2017).

37. Hinek, A. et al. Decreased elastin deposition and high proliferation of fibroblasts from Costello syndrome are related to functional deficiency in the 67-kD elastin-binding protein. Am. J. Hum. Genet. 66, 859-872 (2000).

38. Hinek, A. et al. Myocardial storage of chondroitin sulfate-containing moieties in Costello syndrome patients with severe hypertrophic cardiomyopathy. Am. J. Med. Genet. A 133A, 1-12 (2005).

39. Tarutani, M. et al. Neutrophil-dominant psoriasis-like skin inflammation induced by epidermal-specific expression of Raf in mice. J. Dermatol. Sci. 58, 28-35 (2010).

40. Tarutani, M., Nakajima, K., Takaishi, M., Ohko, K. \& Sano, S. Epidermal hyperplasia induced by Raf-MAPK signaling requires Stat3 activation. J. Dermatol. Sci. 72, 110-115 (2013).

41. Groesser, L. et al. Postzygotic HRAS and KRAS mutations cause nevus sebaceous and Schimmelpenning syndrome. Nat. Genet. 44, 783-787 (2012).
42. Chen, $X$. et al. Endogenous expression of Hras(G12V) induces developmental defects and neoplasms with copy number imbalances of the oncogene. Proc Natl Acad. Sci. USA 106, 7979-7984 (2009).

43. Raguz, J. et al. Epidermal RAF prevents allergic skin disease. Elife 5, e14012 (2016).

44. Marukian, N. V., Levinsohn, J. L., Craiglow, B. G., Milstone, L. M. \& Choate, K. A. Palmoplantar keratoderma in Costello syndrome responsive to acitretin. Pediatr. Dermatol. 34, 160-162 (2017).

45. Bessis, D. et al. Dermatological manifestations in cardiofaciocutaneous syndrome: a prospective multicentric study of 45 mutation-positive patients. Br. J. Dermatol. 180, 172-180 (2019).

46. Untch, B. R. et al. Tipifarnib inhibits HRAS-driven dedifferentiated thyroid cancers. Cancer Res. 78, 4642-4657 (2018).

47. Zhou, L., Yang, K., Wickett, R. R., Andl, T. \& Zhang, Y. Dermal sheath cells contribute to postnatal hair follicle growth and cycling. J. Dermatol. Sci. 82, 129-131 (2016).

48. Andelfinger, G. et al. Hypertrophic cardiomyopathy in Noonan syndrome treated by MEK-inhibition. J. Am. Coll. Cardiol. 73, 2237-2239 (2019).

49. Welsh, S. J. \& Corrie, P. G. Management of BRAF and MEK inhibitor toxicities in patients with metastatic melanoma. Ther. Adv. Med. Oncol. 7, 122-136 (2015).

50. Inoue, S. et al. New BRAF knockin mice provide a pathogenetic mechanism of developmental defects and a therapeutic approach in cardio-facio-cutaneous syndrome. Hum. Mol. Genet. 23, 6553-6566 (2014).

51. Yamamoto, M. et al. A novel atopic dermatitis model induced by topical application with dermatophagoides farinae extract in NC/Nga mice. Allergol. Int. 56, 139-148 (2007).

52. Kobayashi, S. et al. TNF receptor-associated factor 5 limits function of plasmacytoid dendritic cells by controlling IFN regulatory factor 5 expression. J. Immunol. 203, 1447-1456 (2019). 